\title{
Parathyroid Adenoma - From Surgical to Biochemical Cure
}

\author{
Rupa Mehta ${ }^{1}$, Nitin M. Nagarkar², Satish S.S. ${ }^{3}$, Ripu Daman Arora ${ }^{4}$, Jyoti Ranjan Das ${ }^{5}$ \\ 1,2,3,4,5 Department of ENT \& Head Neck Surgery, All India Institute of Medical Sciences, Raipur (AIIMS), Chhattisgarh, India.
}

\section{INTRODUCTION}

Parathyroid glands, minute endocrine glands, located in posterior aspect of thyroid glands secrete parathormone which plays an important role in maintaining calcium homeostasis in the body. The superior and inferior parathyroid glands originate from the $4^{\text {th }}$ and $3^{\text {rd }}$ branchial pouches respectively and migrate to occupy their normal positions in relation to the thyroid gland. ${ }^{1}$ Hyperparathyroidism is defined as hyper functioning of parathyroid gland and can be primary, secondary or tertiary. Primary hyperparathyroidism is due to parathyroid gland proliferative disorders which include parathyroid adenoma, parathyroid hyperplasia, parathyroid carcinoma or in association with other conditions in MEN syndrome. In more than $90 \%$ patients, primary hyperparathyroidism is caused by a single parathyroid adenoma. Very rarely double parathyroid adenomas are seen. Secondary Hyperparathyroidism is caused in response to any chronic hypocalcaemic conditions like renal failure, gastrointestinal malabsorption, dietary rickets \& drugs, like phenytoin, phenobarbital \& laxative. Prolonged secondary hyperparathyroidism leads to tertiary hyperparathyroidism due to autonomous secretion.

The clinical presentation of hyperparathyroidism is classically described as kidney stones, abdominal groans, painful bones, psychic moans, and fatigue overtones. In the initial course of the disease, the patients present with vague symptoms of fatigue, muscle and joint pain, frequent urination, nausea, constipation, and decreased appetite. If high index of suspicion is maintained, they can be conveniently diagnosed by routine blood tests which show increased calcium levels. However, in India still majority of people are diagnosed when they present with palpable neck mass, skeletal manifestations or deranged renal function.

We hereby present 5 cases of parathyroid adenoma managed at our centre over a period of 2 years.

\section{PRESENTATION OF CASE}

\section{Case 1}

A 48-year-old female presented with accidental fracture of left humerus after trivial injury. She presented to Orthopaedics outpatient department where she underwent closed reduction of fracture and cast was applied. X-Ray humerus (Figure 1) was suggestive of diffuse osteopenia with multiple well defined lytic lesions seen in left humerus at upper and mid shaft with pencil thin cortex.

She gave a history of joint pain and muscle weakness. She didn't have any history of body weight loss or loss of appetite. She denied having any neck swelling or dysphagia or change of voice. There was no past history suggestive of any chronic disease.

During workup she was found to be hypercalcaemic. Serum calcium level was $14.9 \mathrm{mg} / \mathrm{dl}$ (normal 9 to $11 \mathrm{mg} / \mathrm{dl}$ ), serum phosphorus level was $2.4 \mathrm{mg}$ / dl (normal 2 to $4.5 \mathrm{mg} / \mathrm{dl}$. Subsequently parathyroid hormone level was tested which was raised - $1900 \mathrm{pg} / \mathrm{ml}$ (normal 14 to $71 \mathrm{pg} / \mathrm{ml}$ ), Alkaline Phosphatase level - 897 IU (normal 33 to $105 \mathrm{IU}$ ) serum magnesium $1.5 \mathrm{mg} / \mathrm{dl}$ (normal 1.7 to $2.4 \mathrm{mg} / \mathrm{dl}$ ), 25 $\mathrm{OH}$ vit D was $12.08 \mathrm{ng} / \mathrm{dl}$ (normal 20 to $50 \mathrm{ng} / \mathrm{dl}$ ). Thyroid profile was normal. Other investigations revealed normal complete blood count and renal parameters.

\author{
Corresponding Author: \\ Dr. Jyoti Ranjan Das, \\ Department of ENT \& Head Neck \\ Surgery, All India Institute of \\ Medical Sciences, Raipur (AIIMS), \\ Chhattisgarh, India. \\ E-mail: jdbegins007@gmail.com
}

DOI: $10.14260 / \mathrm{jemds} / 2021 / 374$

How to Cite This Article:

Mehta R, Nagarkar NM, Satish SS, et al. Parathyroid adenoma - from surgical to biochemical cure. J Evolution Med Dent Sci 2021;10(23):1809-1814, 10.14260/jemds/2021/374 DOI:

Submission 23-02-2021,

Peer Review 14-04-2021,

Acceptance 20-04-2021,

Published 07-06-2021.

Copyright (C) 2021 Rupa Mehta et al. This is an open access article distributed under Creative Commons Attribution License [Attribution 4.0 International (CC BY 4.0)] 
On detailed clinical examination, we found a single small 2 $\mathrm{cm}$ firm, non-tender, swelling over anterior aspect of neck just right side of midline just below the level of thyroid cartilage. Swelling was moving with deglutition. Ultrasonography of the neck revealed a well-defined hyper echoic lesion measuring 3 $\mathrm{X} 3.3 \mathrm{X} 4.4 \mathrm{~cm}$ seen in relation to lower pole of the right lobe of thyroid at posterior aspect. Lesion showed moderate vascularity within. It was consistent with right Parathyroid Adenoma. CECT Neck (Figure 1) was suggestive of large mass located posteroinferior to the right lobe of thyroid, mostly, parathyroid neoplasia. Tc99 sestamibi scintigraphy revealed an area of increased uptake in lower pole of right thyroid with retention of tracer in the delayed images which was suggestive of right inferior parathyroid adenoma.

Diagnosis of primary hyperparathyroidism due to right inferior parathyroid adenoma was made and surgical excision was planned. Right inferior Parathyroidectomy was done to remove right inferior parathyroid adenoma. Parathormone assay 10 mins after excision of the gland showed substantial drop in parathormone levels to $120 \mathrm{pg} / \mathrm{ml}$. Histopathological examination showed abnormal parathyroid consistent with parathyroid adenoma. Postoperatively, the patient showed evidence of hungry bone syndrome with symptomatic hypocalcaemia. She was managed with calcium and Vit D3 supplement. On follow up, her serum calcium levels declined to normal levels (Table 1). Serum intact PTH level on $2^{\text {nd }}$ month follow up was $66 \mathrm{pg} / \mathrm{ml}$ (Table 1). After one-year postop follow up patient was normal and there was no recurrence.

\begin{tabular}{|ccc|}
\hline Day & Serum Calcium & Serum PTH \\
\hline Pre-op & $14.9 \mathrm{mg} / \mathrm{dl}$ & $>1900 \mathrm{pg} / \mathrm{ml}$ \\
$1^{\text {st }}$ post-op & $8.1 \mathrm{mg} / \mathrm{dl}$ & $69.3 \mathrm{pg} / \mathrm{ml}$ \\
$19^{\text {th }}$ post-op & $8.9 \mathrm{mg} / \mathrm{dl}$ & $81 \mathrm{pg} / \mathrm{ml}$ \\
$60^{\text {th }}$ post-op & $8.5 \mathrm{mg} / \mathrm{dl}$ & $66 \mathrm{pg} / \mathrm{ml}$ \\
\hline Table 1. Changes in the Level of Serum Calcium \\
and Serum PTH Postoperatively (Case 1)
\end{tabular}

\section{Case 2}

A 44-year-old lady presented with recurrent swelling over right maxillary region since 2 - 3 years with history of surgery for similar swelling before, On histopathological examination (HPE), it was diagnosed as giant cell tumour of upper jaw. There was no history of recurrent fracture, bone pain, abdominal pain and urinary complaints. There was no significant personal and family history. On clinical evaluation of right maxillary region, a diffuse bony hard swelling was palpable. Patient was advised CT scan from the base of skull to clavicle which showed a heterogeneously enhancing solid cystic mass at right side of neck, posterolateral to the right lobe of thyroid, possibility of parathyroid adenoma (Figure 2). Chest X-ray and USG abdomen were within normal limits.

On biochemical evaluation she was found to be hyper calcaemic and serum parathyroid hormone level was also raised. Serum calcium level was $13.1 \mathrm{mg} / \mathrm{dl}$ (9 - 11mg / dl), serum parathyroid level was $782.1 \mathrm{ng} / \mathrm{ml}(14-71 \mathrm{ng} / \mathrm{ml})$, alkaline phosphatase level - 387 IU (33 - 105 IU). Serum vitamin $\mathrm{D}$, magnesium and phosphorus levels were normal. Thyroid profile was also normal.

Technetium 99 sestamibi scintigraphy (Figure 2) scan revealed scintigraphic evidence of high probability of hyper functioning of right inferior parathyroid adenoma with high metabolic turnover rate. USG guided FNAC was suggestive of right parathyroid swelling consistent with parathyroid lesion. On the basis of all these investigations diagnosis of right inferior parathyroid adenoma was made and the patient was planned for surgical excision. Right inferior parathyroidectomy was done along with right maxillary region and giant cell tumour curettage via lateral rhinotomy approach. Histopathological examination confirmed parathyroid adenoma. Parathormone assay $10 \mathrm{~min}$ after excision of the gland showed substantial drop in parathormone levels to $90 \mathrm{pg} / \mathrm{ml}$. Postoperatively calcium and vitamin D supplementation had to be given to tide over hungry bone syndrome. On regular follow up at 3 months, serum intact PTH level was $64 \mathrm{pg} / \mathrm{ml}$ and serum calcium level was also normal (Table 2).

\begin{tabular}{|ccc|}
\hline Day & Serum Calcium & Serum PTH \\
Pre-op & $13.1 \mathrm{mg} / \mathrm{dl}$ & $782 \mathrm{pg} / \mathrm{ml}$ \\
$1^{\text {st }}$ post-op & $7.9 \mathrm{mg} / \mathrm{dl}$ & $75.8 \mathrm{pg} / \mathrm{ml}$ \\
$30^{\text {th }}$ post-op & $8.3 \mathrm{mg} / \mathrm{dl}$ & $66 \mathrm{pg} / \mathrm{ml}$ \\
$90^{\text {th }}$ post-op & $8.5 \mathrm{mg} / \mathrm{dl}$ & $64 \mathrm{pg} / \mathrm{ml}$ \\
\hline Table 2. Changes in the Level of Serum Calcium \\
and Serum PTH Postoperatively (Case 2)
\end{tabular}

\section{Case 3}

A 13-year-old boy presented in orthopaedics outpatient department for bowing of leg deformity. He was having bone pain since 6 months. He had Genu valgum with pectus excavatum (Figure 3). On examination there was small cystic firm swelling palpable on anterior aspect of the neck just right side of midline at thyroid level. He was evaluated thoroughly and found to be hyper calcaemic (sr calcium: $17.7 \mathrm{mg} / \mathrm{dl}$ ), serum parathyroid hormone (sr PTH: $1254.8 \mathrm{pg} / \mathrm{ml}$ ) and Serum alkaline phosphatase level (sr. ALP: 2350 U / L) were also raised. Serum Vit D, magnesium and phosphorus levels were normal. 24 hours urine calcium was (504 mg / $24 \mathrm{hrs).}$ Thyroid profile was normal.

$\mathrm{X}$ ray of both legs showed bilateral Genu Valgum with decreased bone density with prominent trabeculations \& thinning of cortices. Margins of metaphysis appeared irregular in all visualized bones (Figure 4). USG neck showed heteroechoic mass measuring $3.8 * 2.2 \mathrm{~cm}$ seen in right inferior parathyroid region with increased vascularity suggestive of right inferior parathyroid mass. USG guided FNAC from right inferior parathyroid mass suggestive of parathyroid neoplasm.

Patient was planned for right inferior parathyroidectomy. During surgery right side inferior parathyroid gland was found to be enlarged up to $3 \mathrm{~cm} * 4 \mathrm{~cm}$. Rest all three parathyroid glands were normal on palpation and consistency. So right inferior parathyroid was excised with confirmed parathyroid adenoma histopathologically. Immediately post-operative serum PTH level dropped down to $89 \mathrm{pg} / \mathrm{ml}$ and sr calcium level to $10.1 \mathrm{mg} / \mathrm{dl}$. During postoperative period patient developed hungry bone syndrome and required calcium and vitamin D supplementation. Bone pain reduced substantially.

\begin{tabular}{|ccc|}
\hline Day & Serum Calcium & Serum PTH \\
Pre-op & $17.7 \mathrm{mg} / \mathrm{dl}$ & $1254 \mathrm{pg} / \mathrm{ml}$ \\
$1^{\text {st }}$ post-op & $10.1 \mathrm{mg} / \mathrm{dl}$ & $89 \mathrm{pg} / \mathrm{ml}$ \\
$30^{\text {th }}$ post-op & $7.9 \mathrm{mg} / \mathrm{dl}$ & $61 \mathrm{pg} / \mathrm{ml}$ \\
$90^{\text {th }}$ post-op & $9.1 \mathrm{mg} / \mathrm{dl}$ & $72 \mathrm{pg} / \mathrm{ml}$ \\
\hline \multicolumn{3}{|c|}{ Table 3. Postoperative Changes in Serum } \\
Calcium and PTH Hormone (Case 3)
\end{tabular}

Serum PTH and Serum calcium level came to normal (Table 3). However alkaline phosphatase levels were fluctuating, and the bow leg deformity had not improved. Orthopaedicians have advised correction of the deformity once the alkaline phosphatase levels stabilize. 


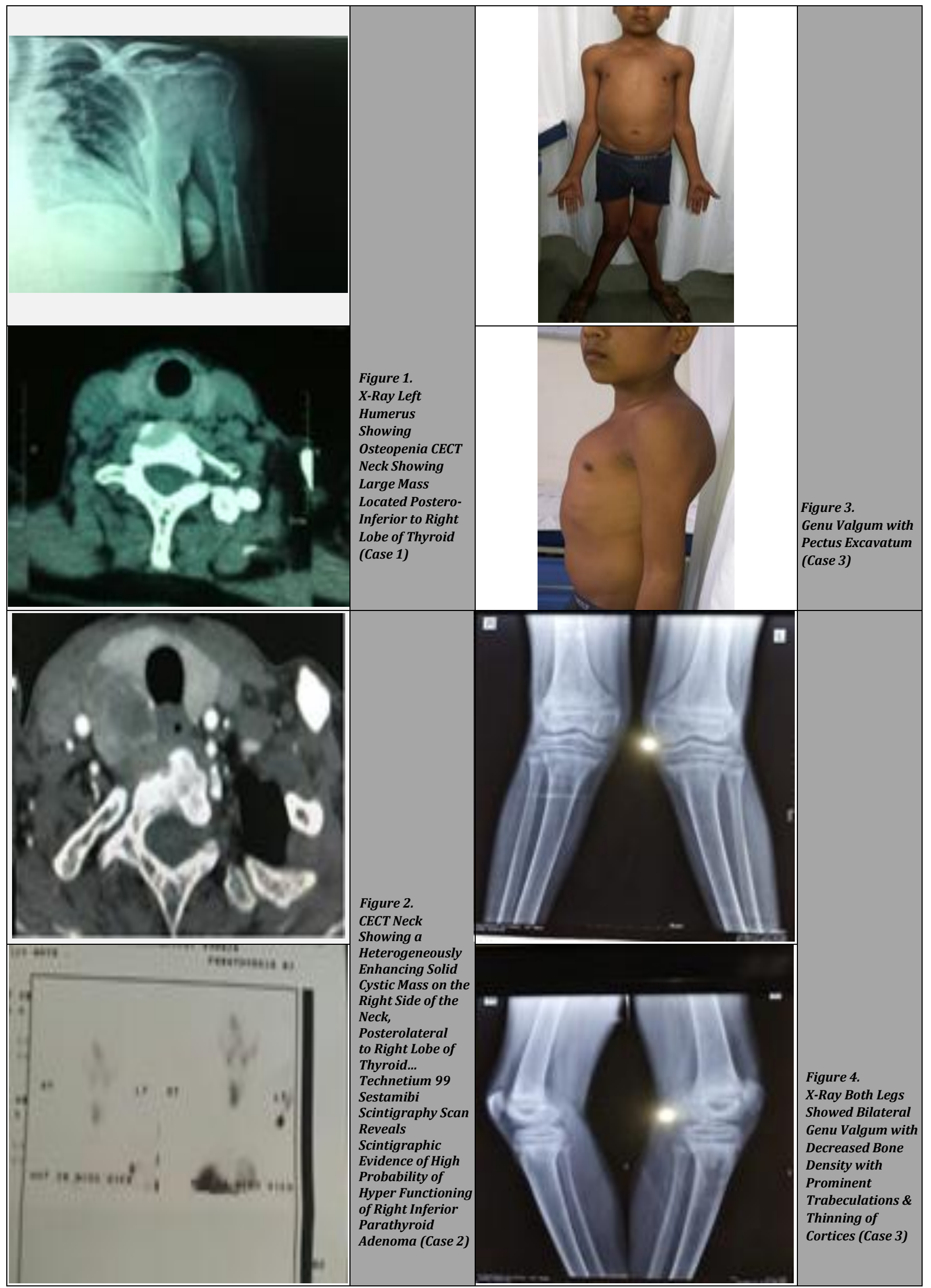




\section{Case 4}

A 28-year-old female presented with history of bony pains for 1 year, started from right leg then involved right arm, left thigh and back. Pain was increasing in nature, aggravated during walking and standing and relieved on sitting or supine position. She was unable to stand up because of pain. She had history of increased thirst and increased frequency of micturition. After 3 months she had swelling over right leg which was small, painful and gradually progressive and she was admitted for radiological investigation. $\mathrm{X}$ ray right tibia showed osteolytic cavity in upper end (Figure 5).

$\mathrm{X}$ ray skull had shown punched out lesions, mottled areas. Other $\mathrm{x}$ rays of upper and lower limbs showed osteoporotic changes. She was diagnosed to have large cystic lesion on proximal tibia and fibrous dysplasia in right humerus. She underwent curettage and excision of cyst. After 2 months she had spontaneous fracture of left tibia, for which plaster had been applied.

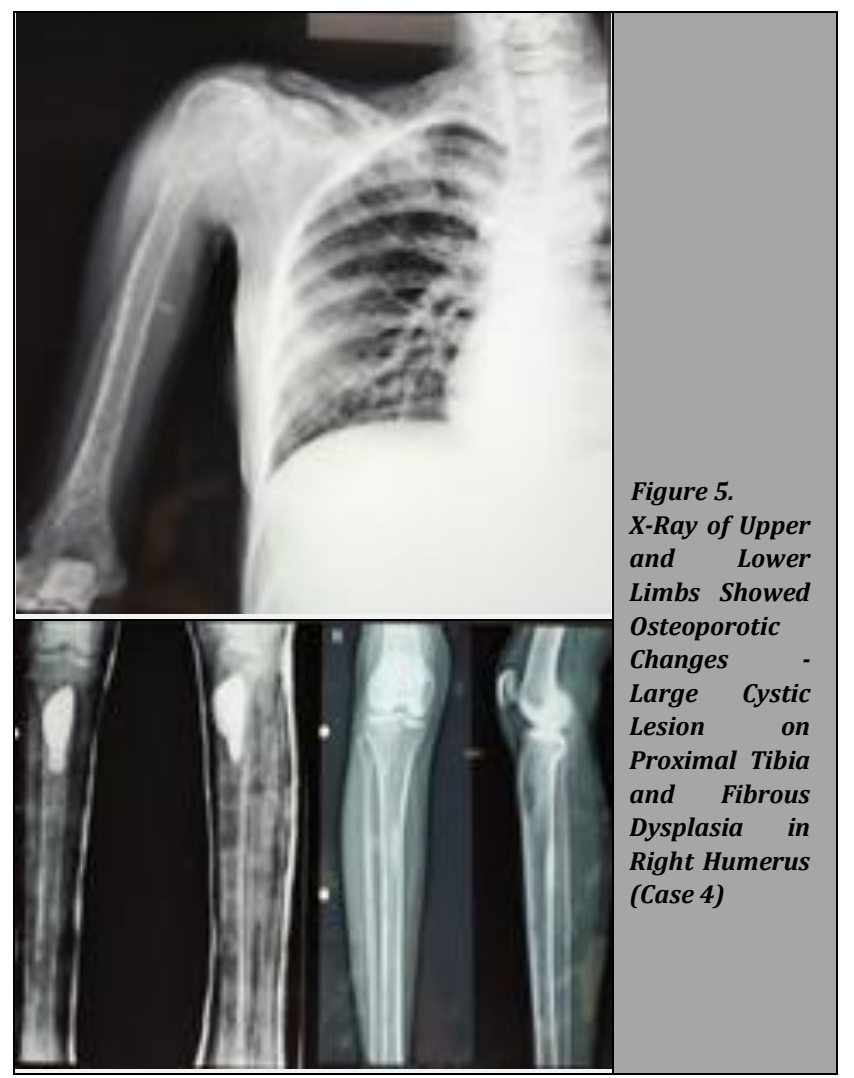

\begin{tabular}{|ccc|}
\hline Day & Serum Calcium & Serum PTH \\
Pre-op & $18.2 \mathrm{mg} / \mathrm{dl}$ & $2000 \mathrm{pg} / \mathrm{ml}$ \\
$1^{\text {st }}$ post-op & $11.2 \mathrm{mg} / \mathrm{dl}$ & $102.5 \mathrm{pg} / \mathrm{ml}$ \\
$3^{\text {th }}$ post-op & $8.5 \mathrm{mg} / \mathrm{dl}$ & $99 \mathrm{pg} / \mathrm{ml}$ \\
$9^{\text {th }}$ post-op & $8.7 \mathrm{mg} / \mathrm{dl}$ & $75 \mathrm{pg} / \mathrm{ml}$ \\
\hline Table 4. Postoperative Changes in Serum Calcium and PTH (Case 4) \\
\hline
\end{tabular}

On detailed examination, there was a small swelling palpated on anterior aspect of neck just right side of midline, which was soft, non-tender and non-pulsatile. No clinically significant cervical lymphadenopathy was seen. Ultrasonography of neck s / o: well defined oval shaped hypoechoic lesion in right side of neck below the right side of thyroid most likely enlarged right inferior parathyroid gland. USG of Abdomen had shown left renal calculus with bilateral grade II renal disease. Sestamibi Parathyroid scan was suggestive of right inferior parathyroid adenoma.
Biochemical investigations revealed hypercalcemia (sr calcium: $18.2 \mathrm{mg} / \mathrm{dl}$ ), serum Alkaline Phosphatase level was raised. Parathyroid Hormone level (sr PTH: > 2000 pg / ml) was substantially increased. Serum TSH, phosphorus and magnesium levels were normal.

Diagnosis of right inferior parathyroid adenoma was made. Patient was planned for Neck exploration. Under general anaesthesia neck was explored and it was found that the right inferior parathyroid gland was enlarged by almost $2.5 \mathrm{~cm}^{*} 2 \mathrm{~cm}$ with aberrant vascularity. It was removed and other three parathyroid glands were examined intraoperatively and found to be normal.

Immediately postoperative serum parathyroid and serum calcium levels were done, and their levels had dropped down to $102.5 \mathrm{pg} \mathrm{/} \mathrm{ml}$ and $11.2 \mathrm{mg} \mathrm{/} \mathrm{dl} \mathrm{respectively.}$ Histopathologically it was confirmed as right inferior parathyroid adenoma.

After 1 month she was better, bone pain was reduced to 70 $\%$ and muscle weakness was reduced. Serum parathyroid and serum calcium came to normal level subsequently (Table 4). Patient was on calcium and vit D supplementation after surgery to tide over hungry bone syndrome.

\section{Case - 5}

A 13-year-old girl presented with bowing of both legs associated with fatigue and joint pain for 6 months duration. She could walk only with support for the last three months. She was evaluated in Departments of Paediatrics and Orthopaedics.

Serum calcium - $12.7 \mathrm{mg} / \mathrm{dl}$, ALP - $1372 \mathrm{u} / \mathrm{l}$ and serum PTH - 447.4pg / ml. USG neck was suggestive of left superior parathyroid adenoma, CECT neck and Technetium $99 \mathrm{~m}$ scans were done to confirm the diagnosis.

She underwent excision of the left superior adenoma. The 10 min parathyroid assay dropped down to $72.4 \mathrm{pg} / \mathrm{ml}$.

She also developed hungry bone syndrome after surgery and was treated with vitamin D and intravenous calcium gluconate. On regular follow up, her serum calcium and PTH levels were found to be normal (Table 5).

\begin{tabular}{|ccc|}
\hline Day & Serum Calcium & Serum PTH \\
Pre-op & $12.7 \mathrm{mg} / \mathrm{dl}$ & $447.4 \mathrm{pg} / \mathrm{ml}$ \\
$1^{\text {st }}$ post-op & $11.2 \mathrm{mg} / \mathrm{dl}$ & $72.4 \mathrm{pg} / \mathrm{ml}$ \\
$30^{\text {th }}$ post-op & $9.1 \mathrm{mg} / \mathrm{dl}$ & $69.0 \mathrm{pg} / \mathrm{ml}$ \\
$90^{\text {th }}$ post-op & $8.7 \mathrm{mg} / \mathrm{dl}$ & $55 \mathrm{pg} / \mathrm{ml}$ \\
\multicolumn{3}{|c}{ Table 5. Postoperative Changes in } \\
Serum Calcium and PTH Hormone (Case 5)
\end{tabular}

\section{DISCUSSION}

Primary hyperparathyroidism is a common endocrine condition causing metabolic bone disease characterized by hypercalcemia and diffuse bone resorption. Most of the cases of primary hyperparathyroidism are due to parathyroid adenoma and usually patients are asymptomatic, incidentally detected with hypercalcemia. Skeletal involvement is mainly as result of increased bone resorption leading to characteristic manifestations like osteitis cystic fibrosa, sub periosteal resorption of distal phalanges, bone cysts and brown tumours. Renal involvement is seen in more than $15 \%$ of cases of 
primary hyperparathyroidism in the form of nephrocalcinosis and nephrolithiasis.

Incidentally detected hypercalcemia, hypophosphatemia, raised levels of alkaline phosphatase and raised intact parathyroid hormone (PTH) levels are all pointing towards primary hyperparathyroidism. Occasionally anterior neck mass may be palpable in case of parathyroid tumour.

The superior and inferior parathyroid glands originate from the $4^{\text {th }}$ and $3^{\text {rd }}$ branchial pouches respectively and migrate caudally to occupy their normal positions in relation to thyroid gland. Ectopic locations of parathyroid gland are posterior mediastinum behind cervical oesophagus, retro sternally in the anterior mediastinum, within the thymus (intrathymic), in the tracheoesophageal groove or unusually with the thyroid parenchyma (intra thyroidal).

In primary hyperparathyroidism, enlargement of single gland or parathyroid adenoma was seen in $80 \%$ of cases. Multiple adenomas or hyperplasia was seen in $15 \%$ to $20 \%$ of patients. Parathyroid carcinoma was seen in $1 \%$ of patient. Primary hyperparathyroidism is again common with syndromes like Men 1 and Men 2A.

Ultrasonography (USG) is a convenient and economical localizing modality and has an acceptable sensitivity and specificity of $73 \%$ and $100 \%$ respectively. ${ }^{2} 4$ D CT scan is another useful radiological modality for parathyroid lesions. It has higher sensitivity and specificity as compared to MRI. Preoperative $99 \mathrm{~m}$ Tc Sestamibi scintigraphy scan helps in localizing the tumour as well as ectopic location in almost 90 $\%$ of patients. ${ }^{3}$ Tc99 together with the thallium technetium subtraction scan and Tc99 with Iodine 123 Subtraction are newer techniques. In case of recurrence of the disease or failed surgery, localization of adenoma by Sestamibi scan is mandatory. ${ }^{4}$ Fusion of Sestamibi TC99 and CT scan is highly valuable in locating ectopic parathyroid. Skeletal X-Rays and dexa bone scan are done to evaluate bone mineral density.

Fine needle aspiration cytology (FNAC) helps to distinguish thyroid gland tissue from parathyroid gland. The cytological features of oxyphil cells and chief cells (the latter devoid of cytoplasm) present in parathyroid adenoma resemble Hurthle cells and lymphocytes respectively. 5

High PTH levels in the aspirates definitively differentiate parathyroid from thyroid tissue. However, in a suspected intra thyroidal parathyroid adenoma, the patient may be subjected to Hemi thyroidectomy when other sites of ectopic gland have been excluded. Biochemical evaluation includes serum calcium, magnesium phosphate, alkaline phosphatase, parathormone, 24-hour urinary calcium, vitamin D, urea creatinine levels.

Various guidelines regarding candidacy for surgery have been proposed by Bilezikian et al. and American academy of endocrine surgery.

Medical management of primary hyperparathyroidism includes oestrogen, bisphosphonates, calcium, and vitamin - D. Primary hyperparathyroidism due to parathyroid adenoma is mainly treated by surgery. Surgical exploration of neck bilaterally is very important to look for all parathyroid glands. Invasion into trachea, oesophagus, recurrent laryngeal nerves and soft tissues are absolute criteria for diagnosis of malignancy of parathyroid gland. Bilateral neck exploration with 4 glands exploration is the classical approach which is at present used only when 4 gland hyperplasia is suspected, concomitant thyroid disorder is present, in patients who have a history of MEN1, MEN2A-PHPT, in whom the parathyroid localization studies are negative or patients in whom the iPTH levels do not fall after unilateral neck exploration. Intra operative histopathologic frozen section examination of excised parathyroid tissue is done. Now with better preoperative scintigraphic localization of the offending gland focused (minimally invasive) parathyroidectomy with intra operative PTH monitoring is widely used and yields equivalent cure rates. Intraoperative PTH assays with a $50 \%$ or more declines from baseline within 10 minutes of excision confirms successful surgery. ${ }^{6}$ Cure rate after parathyroidectomy is defined by normal calcium level 6 months after surgery. PTH levels may however fluctuate after surgery. Patients with normal calcium and high PTH should be evaluated for secondary causes of high PTH. Cure rates are high (95 - 99\%) in experienced hands. Complication rates vary from $1-3 \%$.

Primary hyperparathyroidism occurs in $0.1 \%$ to $0.3 \%$ of general population. Primary hyperparathyroidism, with its varied manifestation and indolent course, is a condition well known to pose a diagnostic dilemma to the clinician. An ectopic location of parathyroid gland may further complicate the issue.

Most of the cases are found to be more than 50 years of age and more in females. Age range of patients in our series ranged from 13 to 50 years. We had one male patient and one female patient aged 13 years. All our patients presented with skeletal abnormalities in the form of fractures, brown cysts, bow legs, pectus carinatum and osteopenia. Two of our patients had full blown picture of rickets. Only three patients had palpable neck swelling. Renal involvement was seen in more than $15 \%$ of cases of primary hyperparathyroidism in the form of nephrocalcinosis. Only one patient in our series had renal stone. Inferior parathyroid was involved in 4 patients; superior parathyroid was involved in one patient. Other presentations could be pain in abdomen, duodenal ulcer, pancreatitis, depression, hypertension. ${ }^{1}$

\section{CONCLUSIONS}

In most of the cases of incidentally detected hypercalcaemia, cause was primary hyperparathyroidism mostly because of parathyroid adenoma. Such variable presentations of primary hyperparathyroidism mislead the diagnosis and treatment. So early pick-up and proper investigation leads to accurate diagnosis and treatment. Our objective should be to diagnose primary hyperparathyroidism cases early before complications occur. Multidisciplinary management is required for optimum management.

Financial or other competing interests: None.

Disclosure forms provided by the authors are available with the full text of this article at jemds.com.

\section{REFERENCES}

[1] Mitlak B, Daly M, Potts JJ. Asymptomatic primary hyperparathyroidism. J Bone Miner Res 1991;6:S10-110.

[2] Bhansali A, Masoodi SR, Bhadada S, et al. Ultrasonography in detection of single and multiple abnormal parathyroid glands in primary hyperparathyroidism: comparison with 
radionuclide scintigraphy and surgery. Clin Endocrinol (Oxf) 2006;65(3):340-5.

[3] Gogas J, Kouskos E, Mantas D, et al. Preoperative TC 99m sestamibi scanning and intraoperative nuclear mapping: are they accurate in localizing parathyroid adenoma? Acta Chir Belg 2003;103(6):626-30.

[4] Thompson GB, Grant CS, Perrier ND, et al. Reoperative parathyroid surgery in the era of sestamibi scanning and intraoperative parathyroid hormone monitoring, Arch Surg 1999;134(7);699-704.

[5] Auger M, Chharbonneau M, Huttner I. Unsuspected intrathyroidal parathyroid adenoma: mimic of lymphocytic thyroiditis in fine needle aspiration specimen. Diagn Cytopathol 1999;21(4):276-9.

[6] De La Cruz VF, Ortega G, Gonzalez S, et al. Pathological intrathyroidal parathyroid glands. Int Surg 1997:82(1);87-90. 